\title{
XAFS Evidence for the Formation of Pb(II) Inner-sphere Adsorption Complexes and Precipitates at the Calcite-Water Interface
}

Ashaki A. Rouff, Evert J. Elzinga, Richard J. Reeder, and Nicholas S. Fisher

\section{Supporting Information:}

$$
3 \text { Pages }
$$

1 Table, 2 Figures 


\begin{tabular}{|c|c|c|c|c|c|}
\cline { 2 - 6 } \multicolumn{1}{c|}{} & \multicolumn{5}{c|}{$\boldsymbol{\mu M}$ initial Pb } \\
\cline { 2 - 6 } \multicolumn{1}{c|}{} & $\mathbf{1}$ & $\mathbf{5}$ & $\mathbf{1 0}$ & $\mathbf{2 0}$ & $\mathbf{6 0}$ \\
\hline Pb-phases SI & & & & & \\
Cerussite & -0.16 & 0.54 & 0.84 & 1.14 & 1.62 \\
Hydrocerussite & -0.74 & 1.35 & 2.26 & 3.16 & 4.59 \\
\hline Batch Uptake & & & & & \\
${ }^{*} \Gamma\left(\right.$ moles Pb per $\left.\mathrm{m}^{2}\right)$ & $1.0 \times 10^{-6}$ & $5.1 \times 10^{-6}$ & $1.1 \times 10^{-5}$ & $2.9 \times 10^{-5}$ & $9.8 \times 10^{-5}$ \\
$\mathrm{~Pb}$ on calcite (ppm) & 2170 & 10491 & 22814 & 59757 & 202484 \\
$\mathrm{~Pb}$ atoms per Ca site & 0.13 & 0.61 & 1.33 & 3.47 & 11.77 \\
& & & & & \\
\hline
\end{tabular}

Table $\mathrm{S} 1$. Saturation indices for $\mathrm{Pb}$-bearing phases and results from batch uptake experiments for relevant sorption samples.

$* \Gamma=\mathrm{Pb}$ sorption density 


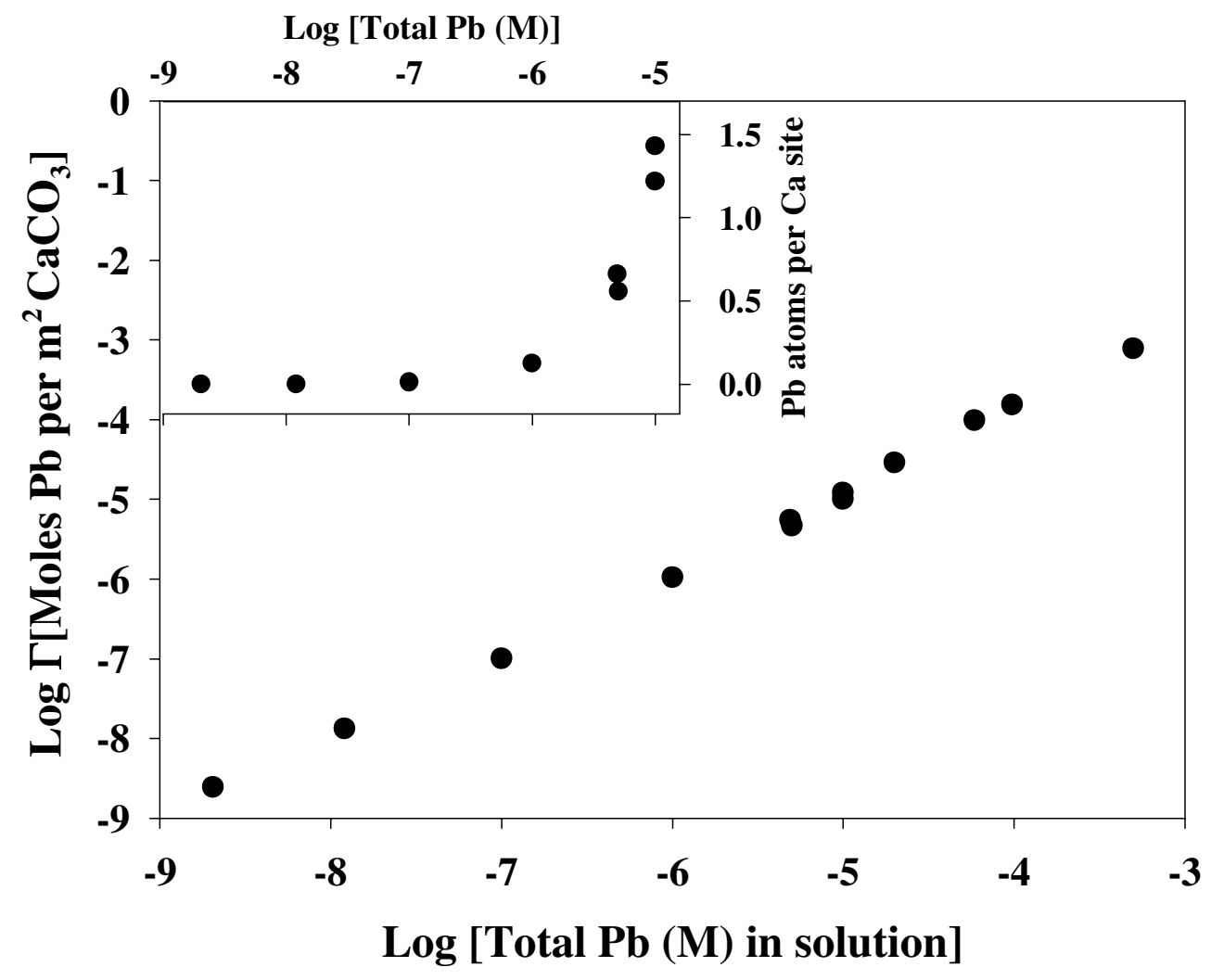

Figure S1. a) The effect of initial $\mathrm{Pb}$ concentration on sorption density $\Gamma$. Inset: $\mathrm{b}$ ) Theoretical site occupancy as a function of initial $\mathrm{Pb}$ concentration for the concentration range $10^{-9}$ to $10^{-5} \mathrm{M} \mathrm{Pb}$ showing the onset of oversaturation. 


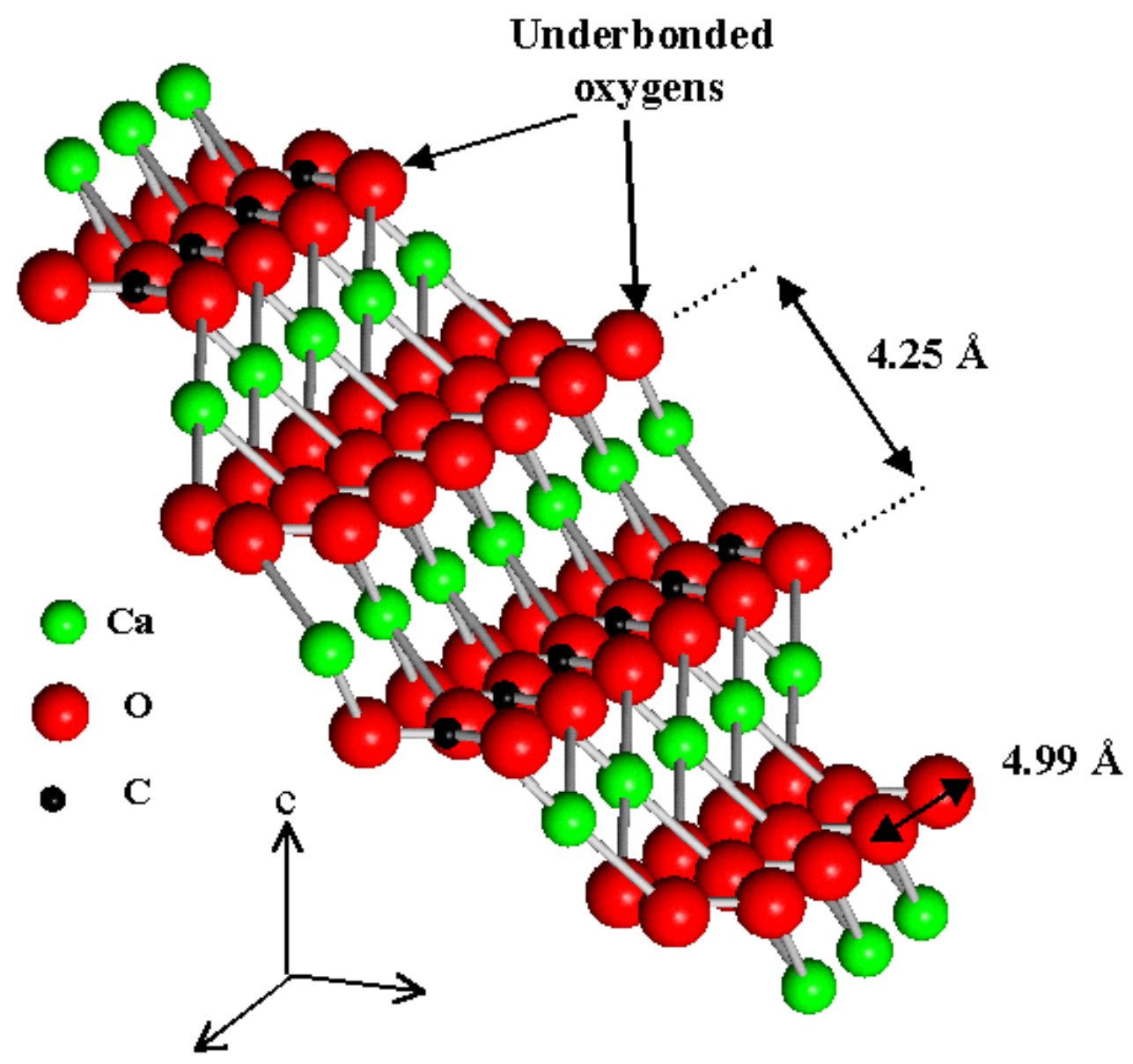

Figure S2. Location and O-O distances of underbonded oxygens on a calcite (10ī4) terrace. These atoms have one unsatisfied bond compared to those at step kink sites, which have two, and therefore more degrees of freedom. O-O separations are too long, and flexibility insufficient to expect binding of the $\mathrm{Pb}$ adsorption complex to two of these oxygen atoms. 